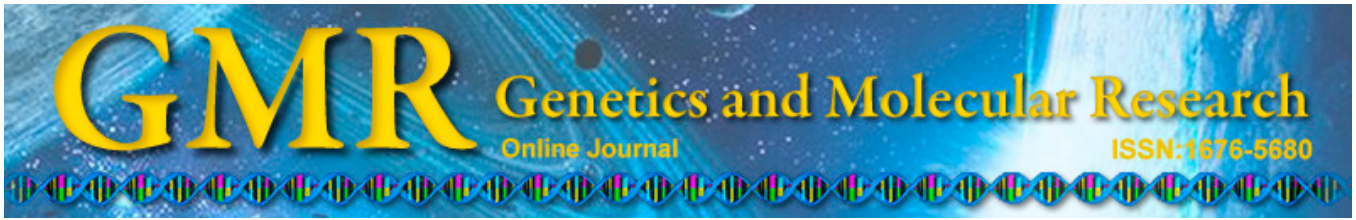

\title{
Diversity, population structure, and evolution of local peach cultivars in China identified by simple sequence repeats
}

\author{
Z.J. Shen ${ }^{1,2}$, R.J. $\mathrm{Ma}^{2}$, Z.X. Cai ${ }^{2}$, M.L. Yu' ${ }^{2}$ and Z. Zhang ${ }^{1}$ \\ ${ }^{1}$ College of Horticulture, Nanjing Agricultural University, Nanjing, China \\ ${ }^{2}$ Institute of Horticulture, Jiangsu Academy of Agricultural Sciences, Nanjing, \\ China \\ Corresponding author: Z. Zhang \\ E-mail: zhangzh@njau.edu.cn
}

Genet. Mol. Res. 14 (1): 101-117 (2015)

Received March 8, 2014

Accepted July 8, 2014

Published January 15, 2015

DOI http://dx.doi.org/10.4238/2015.January.15.13

\begin{abstract}
The fruit peach originated in China and has a history of domestication of more than 4000 years. Numerous local cultivars were selected during the long course of cultivation, and a great morphological diversity exists. To study the diversity and genetic background of local peach cultivars in China, a set of 158 accessions from different ecological regions, together with 27 modern varieties and 10 wild accessions, were evaluated using 49 simple sequence repeats (SSRs) covering the peach genome. Broad diversity was also observed in local cultivars at the SSR level. A total of 648 alleles were amplified with an average of 13.22 observed alleles per locus. The number of genotypes detected ranged from 9 (UDP96015) to 58 (BPPCT008) with an average of 27.00 genotypes per marker. Eight subpopulations divided by STRUCTURE basically coincided with the dendrogram of genetic relationships and could be explained by the traditional groups. The 8 subpopulations were juicy honey peach, southwestern peach I, wild peach, Buddha peach + southwestern peach II, northern peach, southern crisp peach, ornamental peach, and Prunus davidiana + P. kansuensis.
\end{abstract}


Most modern varieties carried the genetic backgrounds of juicy honey peach and southwestern peach I, while others carried diverse genetic backgrounds, indicating that local cultivars were partly used in modern breeding programs. Based on the traditional evolution pathway, a modified pathway for the development of local peach cultivars in China was proposed using the genetic background of subpopulations that were identified by SSRs. Current status and prospects of utilization of Chinese local peach cultivars were also discussed according to the SSR information.

Key words: Peach; Simple sequence repeat (SSR); Local cultivar; Genetic relationship; Population structure; Evolution

\section{INTRODUCTION}

The peach is an economically important fruit species worldwide and is in third position among temperate fruits after apple and pear. The main countries that produce peaches are China, Italy, Spain, and the USA (FAOSTAT, 2012).

Peach originated in China and was domestically planted for more than 4000 years (Faust and Timon, 1995; Wang and Zhuang, 2001). Peach production is not merely an industry but is also culturally important in China because it represents longevity, romance, and sweetness (Wang and Zhuang, 2001; Layne and Bassi, 2008). During the long period of peach cultivation, naturally pollinated seedlings adapting well to the local climate and soil were selected. They were chosen for fruit qualities or for ornamental characteristics and were propagated by seeds or grafting. In this way, the local cultivars were obtained. Chinese Cling, honey peach and Peento are well-known local cultivars from different regions of China. Special characteristics were also selected in local cultivars, including flat nectarines, accessions tolerant to $-30^{\circ} \mathrm{C}$ during winter, cultivars with very low chilling requirement, and cultivars with resistance to certain diseases and insects. Moreover, there are many traditional groups that were defined by the ancient people or modern scientists and were classified by different criteria. For instance, the 4 most famous peach groups for fresh fruits in China are juicy honey peach from Wuxi (Jiangsu Province), Yulu peach from Fenghua (Zhejiang Province), Buddha peach from Feicheng (Shandong Province), and honey peach from Shenxian (Hebei Province) (Wang and Zhuang, 2001).

The use of local Chinese cultivars in cross breeding fostered the development of modern varieties. The well-known Chinese Cling, which is also named ShanghaiShuiMi, is a local cultivar from Shanghai with sweet fruit and melting texture. It was introduced to USA in 1850 and gave rise to Elberta, which is one of the main ancestors of the modern cultivars grown in USA and Europe (Okie et al., 1985; Scorza et al., 1985). Many old varieties from Japan have the genetic background of Chinese Cling (Yamamoto et al., 2003). Another example of the use of a local cultivar is the honey peach. Because very sweet fruits are particularly appreciated in China, many local cultivars were deliberately selected for sweet fruits, giving rise to the honey peach group. This type of local cultivar accelerated the development of sweet taste in occidental countries because they contained the dominant low-acid gene $(D)$ (Layne and Bassi, 2008). The $D$ locus was fine mapped on LG5 using Kiang-Si, a local honey peach cultivar (Boudehri et al., 2009).

The genetic diversity that is found in local cultivars is greatly threatened by current modern varieties, which are preferred by both growers and consumers because of their su- 
perior fruit quality and attractiveness. With large numbers of new varieties being released (about 100 varieties annually worldwide) (Infante et al., 2008), local varieties are gradually disappearing. In China, some traditional varieties, which were used in production 30 years ago, have now disappeared in their places of origin (Gong et al., 2008). Although some useful characteristics are integrated into breeding programs, including accessions resistant to gummosis (Li et al., 2014), ornamental peaches (Hu et al., 2005), and blood-flesh peaches (Shen et al., 2012, 2013a), local cultivars have not been well evaluated, and this evaluation remains an important area for research. The conservation and protection of local cultivars are vital.

Simple sequence repeat (SSR) technology was widely used in many plant species because of its co-dominance, high level of polymorphism, stable amplification, and interspecies transportability. With the development of SSR markers (Cipriani et al., 1999; Testolin et al., 2000; Dirlewanger et al., 2002), many collections of peach were evaluated, including commercial varieties (Aranzana et al., 2010), rootstocks (Serrano et al., 2002), local varieties (Badenes et al., 2002; Cheng and Huang, 2009; Bouhadida et al., 2011), and a large set of accessions (Li et al., 2013). In addition, by using SSR markers, a better understanding of the diversity, genetic relationships, and evolution of peach genetic resources has been gained. Commercial varieties were found to have a narrow genetic background (Aranzana et al., 2003, 2010). Old varieties from Japan had the genetic background of Shanhai Suimitsuto (Yamamoto et al., 2003). However, genetic relationships, backgrounds, and evolution of local cultivars in China have not been emphasized in the previous studies (Cao et al., 2012; Li et al., 2013).

The National Fruit Germplasm Repository of Nanjing (Jiangsu Province, China) has been engaged in the collection and protection of peach genetic resources for over 60 years and has conserved more than 600 accessions including commercial varieties, breeding materials, local cultivars, rootstocks, and wild accessions. Starting with the morphological evaluation of local cultivars (Shen et al., 2013b), the primary objectives of this research were designed to evaluate the genetic diversity, population structure, and genetic background of local Chinese cultivars and to propose their developmental pathways using SSR fingerprints.

\section{MATERIAL AND METHODS}

\section{Plant materials}

One hundred fifty-eight local cultivars conserved in the National Fruit Germplasm Repository of Nanjing (Jiangsu Province, China) were selected for this study (Table S1). These local cultivars were mainly collected before the intensive adoption of modern varieties in China. Among them, 135 accessions were clearly known for their places of origin and were distributed in all 7 ecological regions of peach in China (Wang and Zhuang, 2001). Twentythree accessions (mainly ornamental peach) had unknown places of origin. Besides the local cultivars, 27 released varieties and 10 accessions of wild species were also used to analyze the relationships between modern varieties and local cultivars and the relationships among species, respectively. Altogether, the 195 accessions studied belonged to 4 species, including Prunus persica, $P$. davidiana, $P$. kansuensis, and $P$. ferganensis, and also included interspecies hybrids from $P$. persica $\times$ P. davidiana. No accession from $P$. mira was used because more investigations were needed to choose the representative accessions. Local cultivars were mainly used for fresh fruit or as ornamentals while wild accessions were mainly used as rootstocks. The pedigrees of local cultivars were mostly unknown. 


\section{DNA isolation and SSR amplification}

Young expanded terminal leaves were collected and used for DNA extraction according to the accepted protocol (Bernatzky and Tanksley, 1986). Forty-nine SSR markers distributed along 8 linkage groups of the Prunus reference map were used for genotyping (Table S2). The SSRs that were used were similar to those in previous studies (Aranzana et al., 2010; Li et al., 2013). Polymerase chain reaction (PCR) amplifications were carried out as described by Aranzana et al. (2003) using fluorescence-labeled primers. Amplified fragments were detected by capillary electrophoresis with the automatic sequencer ABI/Prism 3100 (Applied Biosystems, PerkinElmer, Foster City, CA, USA). Alleles were read by GeneMapper and using GeneScan $^{\mathrm{TM}} 500$ LIZ $^{\circledR}$ (Applied Biosystems, PerkinElmer, USA) as a size standard.

\section{Data analysis}

Genetic parameters of SSR amplification were calculated by POPGENE32 (Yeh et al., 1999), including average number of alleles per locus, effective number of alleles, observed heterozygosity, expected heterozygosity, Wright's fixation index, power of discrimination, Shannon's information index, and number of genotypes. For genetic relationship analysis, SSR alleles from the same locus were scored as $0 / 0.5 / 1$, representing absence/heterozygous allele/ homozygous allele, respectively (Aranzana et al., 2003). Genetic distances between cultivars were calculated with Nei's parameter (Nei et al., 1983) using the program NTSYSpc 2.1 (Rohlf, 2000). The unweighted pair-group method with arithmetic average was used for clustering.

Forty SSRs were used to analyze the population structure because 9 markers (UDP96005, СРPCT026, СРРCT029, UDP98-025, ВРPCT024, СРPCT005, ВРРСТ015, СРSCT006, and pchgms6) were relatively close to other markers on the linkage map (Table S2 $)$. The population structure was analyzed using Structure version 2.3.1 (Pritchard et al., 2000). The parameters for STRUCTURE were the same as those used for commercial varieties (Aranzana et al., 2010): under the assumption of the admixture model and correlated allele frequency (Falush et al., 2003), with a 100,000 burn-in period and 1,000,000 Markov chain Monte Carlo repetitions. Ten independent runs were performed by setting $\mathrm{K}$ equal to values that ranged from 1 to 20 .

\section{RESULTS}

\section{Allelic variation, fixation index, and heterozygosity measures}

A total of 648 alleles were amplified by 49 SSRs with an average of 13.22 observed alleles per locus (Table 1). The number of observed alleles varied from 5 (BPPCT024 and UDP96015) to 26 (BPPCT015) among SSRs. Compared to the number of observed alleles, the estimated number of effective alleles is relatively low (4.14) because 152 alleles only existed in a single accession, mostly in $P$. davidiana and P. kansuensis. Among the observed alleles, $53.5 \%$ appeared at frequencies lower than $2.0 \%$, which suggested a high level of diversity in local cultivars. The observed heterozygosity ranged from 0.08 (pchgms2) to 0.56 (CPPCT022) with an average value of 0.42 . The expected heterozygosity, with an average value of 0.71 , was higher for each marker than the observed heterozygosity. The positive fixation index was found for each marker, and the average value was 0.42 . The average of power of discrimination was 0.84 , and BPPCT008 had the highest ability to discriminate two random cultivars 
(0.96). The number of detected genotypes ranged from 9 (UDP96015) to 58 (BPPCT008) with an average of 27.00 genotypes per marker.

Using 49 SSRs, 191 of 195 accessions could be discriminated. The same genotype was observed between DaHongHua and ZaoFengHuaYuLu, and between BaiMangPanTao and FengHuaPanTao.

\begin{tabular}{|c|c|c|c|c|c|c|c|c|}
\hline SSR marker & $A$ & $A e$ & $H_{\mathrm{O}}$ & $H_{\mathrm{E}}$ & $F$ & No. of genotypes & $P D$ & $I$ \\
\hline UDP96018 & 13 & 4.16 & 0.43 & 0.76 & 0.43 & 27 & 0.88 & 1.75 \\
\hline СРРСТ027 & 10 & 3.60 & 0.45 & 0.72 & 0.37 & 16 & 0.86 & 1.61 \\
\hline UDP96005 & 11 & 4.03 & 0.55 & 0.84 & 0.34 & 27 & 0.88 & 1.98 \\
\hline EPPCU1090 & 10 & 4.02 & 0.46 & 0.75 & 0.39 & 18 & 0.88 & 1.54 \\
\hline СРРСТ026 & 16 & 5.71 & 0.49 & 0.83 & 0.40 & 35 & 0.92 & 2.01 \\
\hline pchgms3 & 6 & 3.80 & 0.44 & 0.74 & 0.40 & 12 & 0.87 & 1.56 \\
\hline ВРPCТ020 & 9 & 2.60 & 0.33 & 0.62 & 0.46 & 15 & 0.77 & 1.25 \\
\hline СРРСТ042 & 18 & 5.16 & 0.37 & 0.81 & 0.55 & 39 & 0.89 & 2.00 \\
\hline СРРСТ029 & 12 & 5.72 & 0.44 & 0.83 & 0.47 & 37 & 0.92 & 1.97 \\
\hline ps9f8 & 16 & 4.52 & 0.42 & 0.78 & 0.46 & 32 & 0.88 & 1.84 \\
\hline СРРСТ044 & 12 & 3.33 & 0.45 & 0.78 & 0.42 & 23 & 0.87 & 1.89 \\
\hline UDP98025 & 7 & 4.61 & 0.42 & 0.79 & 0.46 & 18 & 0.88 & 1.65 \\
\hline ВРРСТ001 & 18 & 4.92 & 0.50 & 0.8 & 0.38 & 38 & 0.91 & 2.03 \\
\hline UDP96013 & 14 & 3.64 & 0.43 & 0.73 & 0.41 & 25 & 0.86 & 1.61 \\
\hline pchgms1 & 6 & 2.34 & 0.30 & 0.57 & 0.47 & 11 & 0.72 & 1.01 \\
\hline ВРРСТ 024 & 5 & 3.92 & 0.43 & 0.75 & 0.42 & 15 & 0.88 & 1.46 \\
\hline PceGA34 & 12 & 2.19 & 0.31 & 0.54 & 0.43 & 20 & 0.69 & 1.15 \\
\hline ВРРСТ007 & 16 & 5.66 & 0.53 & 0.83 & 0.36 & 33 & 0.92 & 1.96 \\
\hline ВРРСТ039 & 18 & 1.79 & 0.34 & 0.44 & 0.22 & 27 & 0.63 & 1.15 \\
\hline СРРСТ002 & 7 & 3.51 & 0.41 & 0.72 & 0.42 & 14 & 0.85 & 1.42 \\
\hline UDP96008 & 11 & 2.68 & 0.31 & 0.63 & 0.51 & 21 & 0.76 & 1.30 \\
\hline pchgms 2 & 11 & 1.35 & 0.08 & 0.26 & 0.70 & 16 & 0.30 & 0.65 \\
\hline СРРСТ005 & 10 & 2.32 & 0.40 & 0.64 & 0.38 & 11 & 0.78 & 1.46 \\
\hline UDP98024 & 17 & 4.17 & 0.44 & 0.76 & 0.42 & 37 & 0.88 & 1.81 \\
\hline UDP96003 & 20 & 6.73 & 0.53 & 0.85 & 0.37 & 48 & 0.93 & 2.26 \\
\hline ВРРСТ015 & 26 & 6.34 & 0.36 & 0.84 & 0.57 & 49 & 0.91 & 2.30 \\
\hline СРРСТ046 & 12 & 5.17 & 0.24 & 0.81 & 0.71 & 22 & 0.87 & 1.79 \\
\hline СРРСТ040 & 7 & 3.84 & 0.50 & 0.74 & 0.32 & 15 & 0.88 & 1.59 \\
\hline UDP97401 & 12 & 2.96 & 0.35 & 0.66 & 0.47 & 19 & 0.80 & 1.42 \\
\hline ВРРСТ017 & 9 & 4.14 & 0.36 & 0.56 & 0.48 & 19 & 0.92 & 2.20 \\
\hline CPSCT006 & 12 & 4.55 & 0.49 & 0.78 & 0.38 & 28 & 0.90 & 1.76 \\
\hline ВРРСТ037 & 14 & 2.81 & 0.42 & 0.65 & 0.35 & 24 & 0.80 & 1.44 \\
\hline СРРСТ013 & 10 & 2.19 & 0.33 & 0.55 & 0.39 & 16 & 0.68 & 1.15 \\
\hline ВРРСТ038 & 16 & 6.25 & 0.51 & 0.84 & 0.39 & 41 & 0.93 & 2.18 \\
\hline ВРРСТ014 & 12 & 1.53 & 0.26 & 0.35 & 0.26 & 14 & 0.50 & 0.76 \\
\hline UDP96001 & 11 & 5.54 & 0.48 & 0.82 & 0.42 & 31 & 0.92 & 1.91 \\
\hline ВРРСТ008 & 22 & 10.09 & 0.55 & 0.90 & 0.39 & 58 & 0.96 & 2.58 \\
\hline СРРСТ015 & 17 & 4.07 & 0.40 & 0.76 & 0.48 & 32 & 0.86 & 1.91 \\
\hline pchems5 & 11 & 3.60 & 0.43 & 0.72 & 0.40 & 20 & 0.86 & 1.53 \\
\hline ВРРСТ 025 & 16 & 5.06 & 0.48 & 0.80 & 0.41 & 44 & 0.91 & 2.07 \\
\hline СРРСТ030 & 16 & 3.25 & 0.55 & 0.69 & 0.20 & 30 & 0.85 & 1.69 \\
\hline СРРСТ022 & 24 & 6.24 & 0.56 & 0.84 & 0.34 & 52 & 0.93 & 2.26 \\
\hline pchgms6 & 19 & 5.68 & 0.52 & 0.83 & 0.37 & 37 & 0.93 & 2.15 \\
\hline СРРСТ033 & 13 & 3.84 & 0.38 & 0.74 & 0.49 & 29 & 0.86 & 1.67 \\
\hline PMS02 & 20 & 2.61 & 0.39 & 0.62 & 0.37 & 35 & 0.77 & 1.62 \\
\hline UDP96015 & 5 & 2.94 & 0.40 & 0.66 & 0.40 & 9 & 0.82 & 1.69 \\
\hline ВРРСТ006 & 10 & 6.52 & 0.49 & 0.85 & 0.42 & 30 & 0.93 & 2.14 \\
\hline СРРСТ006 & 7 & 2.28 & 0.27 & 0.56 & 0.52 & 12 & 0.70 & 1.09 \\
\hline UDP98409 & 22 & 4.78 & 0.44 & 0.79 & 0.44 & 42 & 0.89 & 2.01 \\
\hline Average & 13.22 & 4.14 & 0.42 & 0.72 & 0.42 & 27.00 & 0.84 & 1.70 \\
\hline
\end{tabular}

$A=$ number of alleles per locus; $A e=$ effective number of alleles; $H_{\mathrm{O}}=$ observed heterozygosity; $H_{\mathrm{E}}=$ expected heterozygosity; $F=$ Wright's fixation index; $P D=$ power of discrimination; $I=$ Shannon's information index. 


\section{Genetic relationships}

Traditional peach groups that were defined by the ancients or modern scientists (Wang and Zhuang, 2001) are shown in bar chart I (Figure 1). Very close genetic relationships were found among 3 groups: flat peaches from south China, Yulu peaches, and accessions closely related to Chinese Cling (Figure 1, Node 1). Buddha peaches from Shandong Province and honey peaches from north China (Beijing, Hebei, and Shandong) were clustered together, and they were grouped with northwest peaches (Xinjiang, Shaanxi, and Gansu) into a subgroup (Figure 1, Node 2). Crisp peaches from southern China were assembled together in the dendrogram (Figure 1, Node 3). Most accessions from Yunnan Province, a place that is very close to the center of origin of peaches, were clustered into a group (Figure 1, Node 4), while some accessions were clustered nearby in Node 1. Although ornamental peaches were relatively concentrated (Nodes 5-1 and 5-2), a broad diversity was found, which was expressed in terms of the genetic distances of the clustering nodes. Ornamental peaches with dwarf and weeping tree habits were mainly clustered in Node 5-1, and those with a normal tree habit were mainly clustered in Node 5-2. All 3 interspecific ornamental peaches between P. persica and P. davidiana were clustered in Node 5-2.

Accessions were sorted by fruit type, use, germplasm type, and species to observe the genetic relationships of different types of genetic resources (Figure 1). When sorted by fruit type (bar chart F), flat peaches from south China were clustered into a group on the top of the dendrogram with a very low genetic distance, while flat peaches from north China, WuYueXianBianGan and XinJiangPanTao, were clustered outside of the south and in the middle. Nectarines and flat nectarines were relatively distant, except WanLiGuang and TianLiGuang, which are 2 old cultivars that are both from XinJiang. When sorted by use (bar chart $\mathrm{U})$, ornamental peach varieties were mainly distributed at the bottom, except for 2 red-leaf accessions, which were clustered on the top half of the dendrogram. P. kansuensis and P. davidiana were used as rootstocks in central, north, and northwest China, and they were clustered at the bottom. Wild accessions of P. persica were mainly used as rootstocks in south China, and they were not close in the dendrogram, suggesting their diversity. When sorted by germplasm type (bar chart G), modern varieties were clustered inside the local cultivars and were mainly distributed in the upper half of the dendrogram. When sorted by species (bar chart S), P. kansuensis and $P$. davidiana were clustered outside of $P$. persica at the bottom. Three interspecies accessions of $P$. persica $\mathrm{x} P$. davidiana were clustered inside $P$. persica. Five accessions of $P$. ferganensis were clustered inside the $P$. persica accessions in the middle of the dendrogram. Most of the $P$. ferganensis accessions, 4 of the 5 accessions, were very close, while XinJiangPanTao (a flat peach) was relatively far from other $P$. ferganensis accessions.

\section{Population structure}

By STRUCTURE analysis, Q values of each accession with different population numbers were shown by bar charts (Figure 1). Increasing the number of populations from $\mathrm{K}=2$ to 10 , subpopulations were formed gradually, and tiny changes were observed when $K \geq 8$. Eight subpopulations divided by structure basically coincided with the genetic relationships of the traditional groups and could be biologically interpreted.

When $\mathrm{K}=8$, the subpopulation colored in red represents juicy honey peach with a soft melting flesh texture and sweet taste. Three traditional groups, Yulu peach, flat peach from 

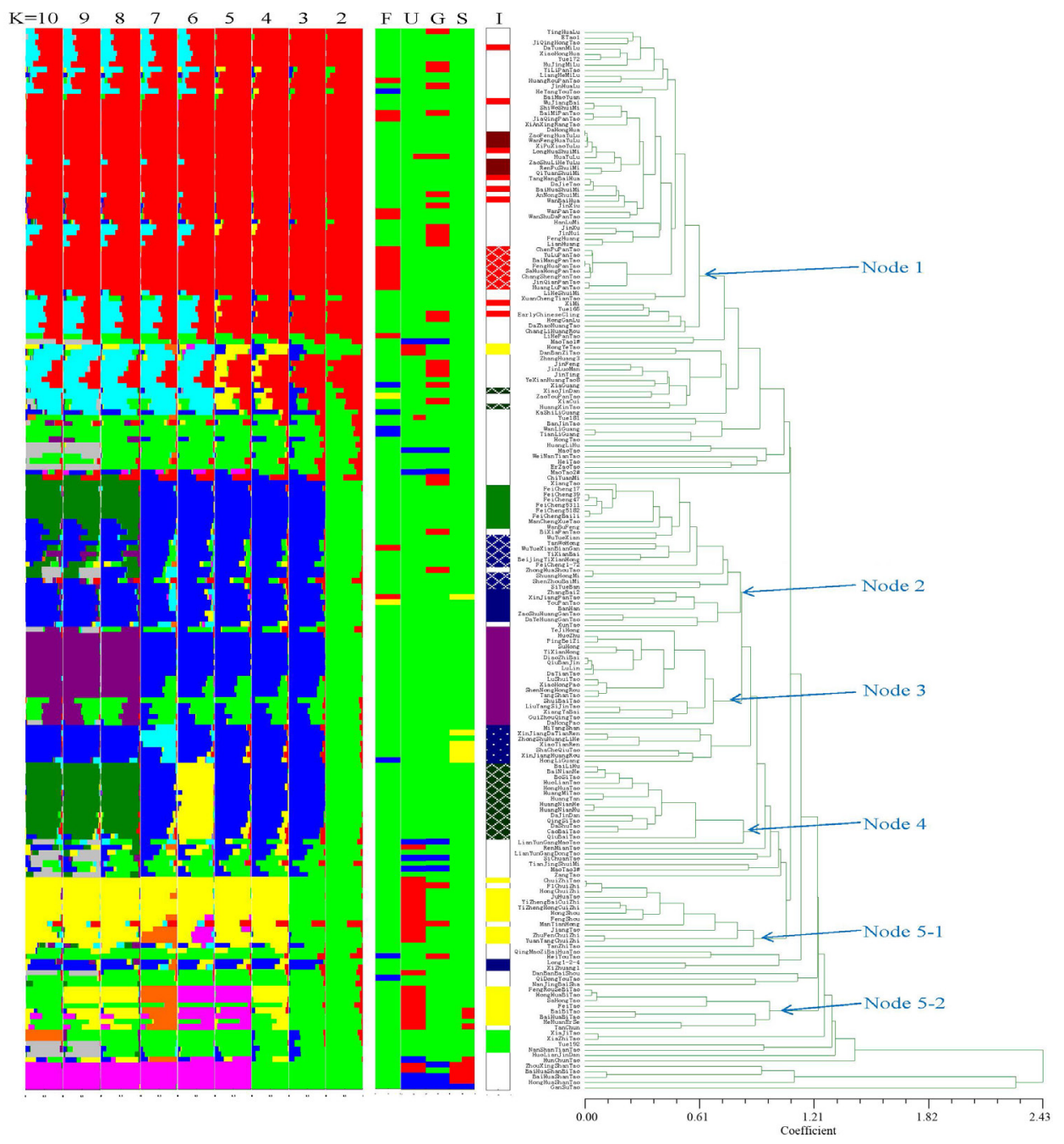

Figure 1. Population structure, sorting, and dendrogram of 195 peach accessions. Population structures with different numbers of populations ( $\mathrm{K}=2$ to 10$)$ are shown on the left. Accessions sorted by fruit type (F), use (U), germplasm type $(\mathrm{G})$, and species $(\mathrm{S})$ are shown in the middle. When sorted by fruit type $(\mathrm{F})$, peach, flat peach, nectarine, and flat nectarine are green, red, blue, and yellow, respectively. When sorted by use (U), accessions that are used for fruit, ornamental, and rootstock purposes are green, red, and blue, respectively. When sorted by germplasm type $(\mathrm{G})$, local cultivars, modern varieties, and wild accessions are green, red, and blue, respectively. When sorted by species (S), Prunus persica, P. davidiana, P. ferganensis, and P. kansuensis are green, red, yellow, and blue, respectively. Information (I) about the traditional groups is indicated by bar chart I. Accessions related to Chinese Cling are red. Yulu peaches with a typical soft melting texture from Zhejiang province are dark red. Flat peaches from south China are white net with red background. Buddha peaches are green. Honey peaches from Beijing, Hebei, and Shandong are white net with blue background. Typical accessions from northwest China are blue. Crisp peaches from south China are violet. Accessions labeled with white dots on a blue background are from XinJiang and are mostly P. ferganensis. Peaches from southwestern China are white net with green background. Ornamental peaches are yellow. Accessions labeled in green are from southeastern China. A dendrogram that was drawn using Nei's distance is shown on the right. 
southern China, and accessions related to Chinese Cling, were included in the juicy honey peach subpopulation. Accessions colored in light blue were mostly in an admixed structure, and most of them were modern varieties. This genetic background could be traced to 3 old cultivars, XiaoJinDan and HuangXinTao from Yunnan Province and ZhangHuang3 from central China, because they carried a large proportion of the light blue background with $\mathrm{Q}$ values of $0.87,0.68$, and 0.77 , respectively. They were defined as southwestern peach I, because Yunnan Province was closer to the center of origin than central China. The light green subpopulation was wild peach with small fruits. Two types of peach, Buddha peach and southwestern peach II, which had the same structure, were included in the green subpopulation. The blue, violet, and yellow populations were northern peach, southern crisp peach, and ornamental peach, respectively. $P$. davidiana and $P$. kansuensis were included in the pink subpopulation. In summary, when $\mathrm{K}=8$, the subpopulations that were divided by structure were juicy honey peach, southwestern peach I, wild peach, Buddha peach + southwestern peach II, northern peach, southern crisp peach, Ornamental peach, and P. davidiana + P. kansuensi.

Six of 8 subpopulations were generated steadily with the increasing number of populations (Figure 1). Juicy honey peach and southwestern peach I were divided from the others when $\mathrm{K}=2$, and the 2 subpopulations separated from each other when $\mathrm{K} \geq 6$. Three subpopulations, southern crisp peach, northern peach, and Buddha peach + southwest peach II, were formed simultaneously when $\mathrm{K} \geq 8$. Buddha peach and southwestern peach II shared the same population structure when $\mathrm{K} \geq 8$. The $P$. davidiana and $P$. kansuensis subpopulation was formed when $\mathrm{K}=5$, and the structure was stable when $\mathrm{K} \geq 7$. However, 2 subpopulations, ornamental peach and wild peach, were observed to have some changes during with the increasing number of populations. Some accessions of ornamental peach shifted to other subpopulations when $\mathrm{K}=4$ to 10 . This indicated the complexity of their genetic background. The wild peach subpopulation was formed when $\mathrm{K}=5$, and it was stable from $\mathrm{K}=5$ to 8 , but tiny changes were observed when $\mathrm{K}>8$. Some accessions from the wild peach subpopulation could be split and subdivided into new subpopulations when $\mathrm{K}=9$ and 10, indicating the potential further diversity in this subpopulation. Therefore, $\mathrm{K}=8$ captured the main structure of the accessions tested.

\section{Distribution and genetic background of local cultivars}

Using pie charts that were drawn according to the portion assigned to the subpopulations, accessions were shown in the Chinese map at their original province (Figure 2).

Juicy honey peach (red), including flat peach from south China, Yulu peach, and accessions related to Chinese Cling, were mainly distributed in Jiangsu, Zhejiang, and Shanghai along the east coast in the south. Traditionally, consumers from this region prefer peaches or flat peaches with lots of juicy, very sweet flavor, white flesh, pink coloration, and cling stone.

Southern crisp peach (violet) was mainly located in the regions along the Yangtze River. Southern crisp peach is characterized as a crisp, firm texture when ripe and mealy when fully matured. The special mealy texture, which loses juice and becomes powdery, is different from the melting, non-melting, and stony hard textures observed in other varieties. Some crisp peach cultivars were still used in production in some regions because some consumers preferred their texture and free stone habit.

Southwestern peach II (Yunnan Province) and Buddha peach (Shandong Province) shared the same structure (green) although they are geographically distant by about $3000 \mathrm{~km}$. 
Buddha peaches are famous for their sweet taste, big fruit size, round shape, white flesh, low flower density, and relatively high chilling hours. Most accessions of Southwestern peach II are different from Buddha peach and have yellow flesh, cling stone, and non-melting texture.

Northern peach (blue) had a broad distribution from the east coast in the north (Hebei and Shandong Province) to the west (Xinjiang autonomous region), but it mainly appeared in the north region of the Yellow River. All 6 accessions of $P$. ferganensis were included in the northern peach subpopulation. In general, northern peach has a slow melting habit or nonmelting texture. However, some accessions, such as YiXianBai and YanWoHong, have a very firm texture similar to Yumyeoung, which was a typical stony hard genotype.

Wild peaches of $P$. persica (light green) were distributed widely, covering almost all of the peach regions. Southwestern peach I (light blue) also had a broad distribution. Accessions of $P$. davidiana and $P$. kansuensis originated in central China. Because the places of origin of most ornamental peaches were unknown (Table S1), only some accessions with an admixed structure (yellow) could be found in most regions.

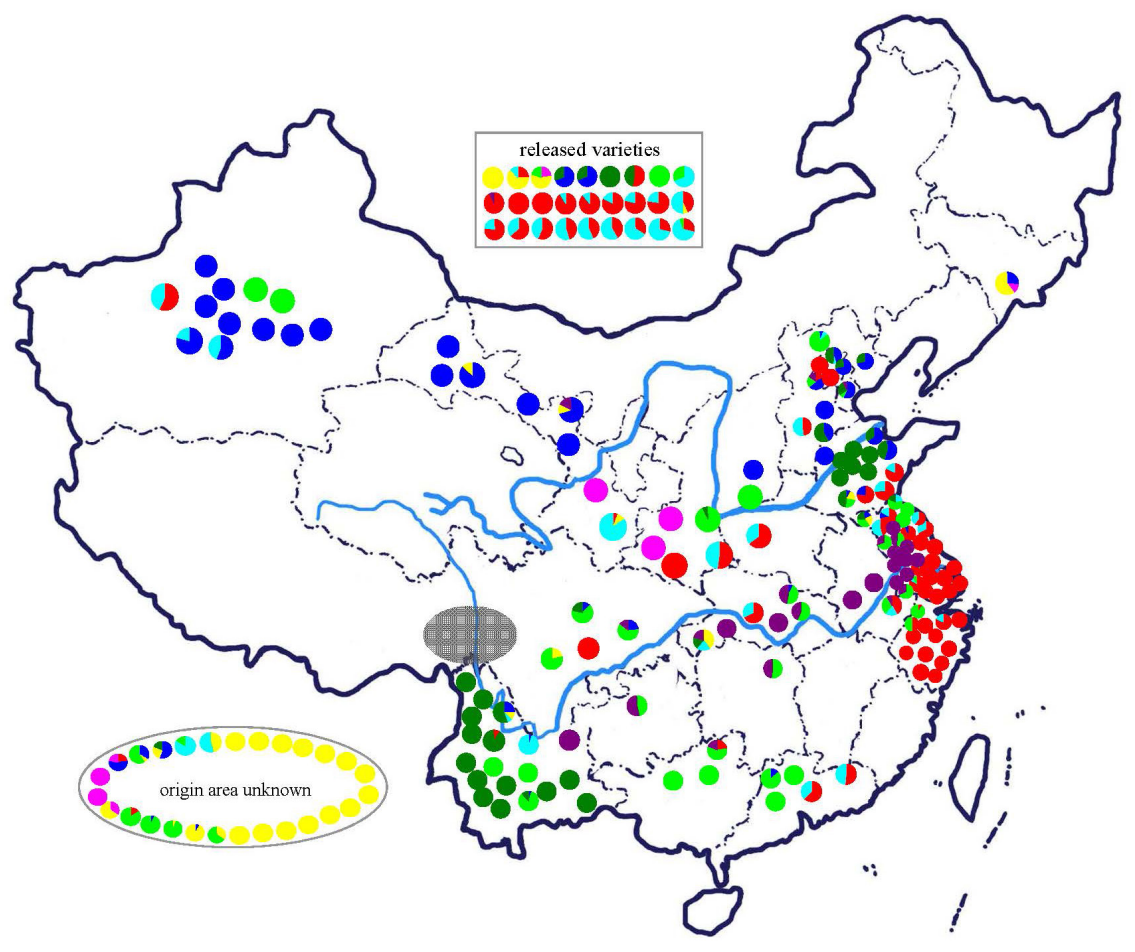

Figure 2. Distribution and population structure $(K=8)$ of the accessions. The pie chart of each accession was drawn according to the composition of structure ( $Q$ value) when $K=8$. Q values lower than 0.05 were removed to better show the main structures. Each portion of the structure was colored in the same way as the bar chart in Figure $1(\mathrm{~K}=8)$. The 8 subpopulations and their corresponding colors were juicy honey peach in red, south-western peach I in light blue, wild peach in light green, Buddha peach + south-western peach II in green, northern China in blue, southern crisp peach in violet, ornamental peach in yellow, and $P$. davidiana $+P$. kansuensis in pink. Local cultivars represented by the pie chart were assembled according to their original province when known. Local cultivars in the ellipse were accessions with unknown origin. Modern varieties were grouped in the rectangle. The ellipse in shadow in the map was the original center of peach diversity as described by Wang and Zhuang (2001). 


\section{Genetic background and pedigree of modern varieties}

The pedigrees of modern varieties (Yu, 2004) were used to analyze the inheritance of genetic backgrounds (Figure 3). Most of the modern varieties carried the background of juicy peach and southwestern peach I, and they were admixed in different proportions (Figures 1 and 2).

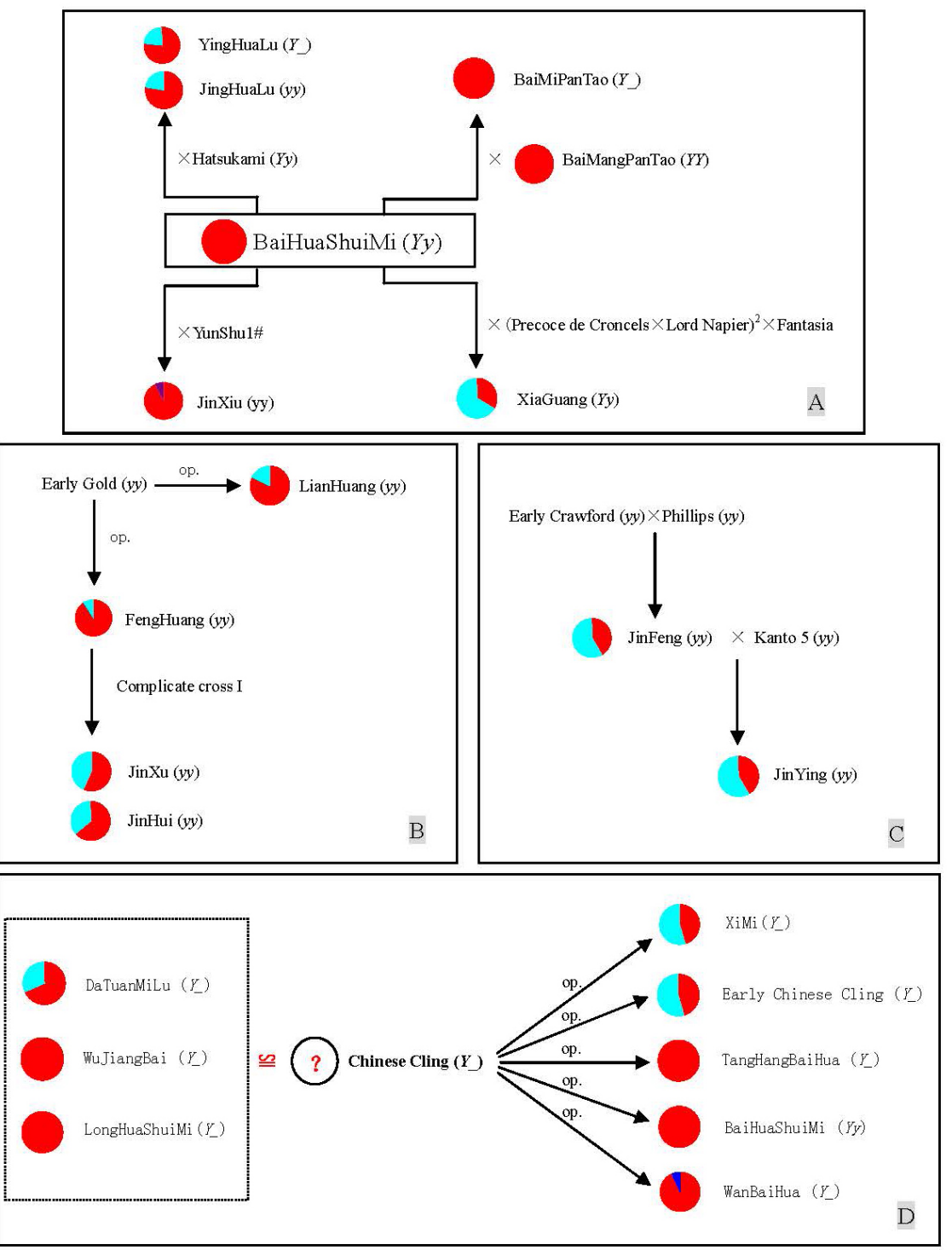

Figure 3. Inheritance of genetic background using pedigrees. A. Five modern varieties sharing the common background of BaiHuaShuiMi. B. Pedigree of 4 modern yellow-flesh peaches. Complicated cross I was (Golden peach x Tuscan-43) x (Okayama 3 x Orange cling-9) x Fenghuang. C. Pedigree of 2 yellow-flesh peaches sharing a similar background. D. Chinese Cling-related accessions and their structures. $Y$ and $y$ are genotypes of flesh color, white $(Y)$ is dominant to yellow $(y)$. 
The genetic background according to the structure was observed to be inherited stably (Figure 3). BaiMiPanTao is actually a typical juicy honey peach with a flat shape, white flesh, and soft melting texture. By taking pedigree into account, the juicy honey peach background of BaiMiPanTao could be obtained by crossing 2 accessions of juicy honey peaches (Figure $3 \mathrm{~A})$. YinHuaLu and JinHuaLu, 2 varieties that were selected from the same cross, carried similar portions of juicy honey peach and southwestern peach I, although their flesh colors are white and yellow, respectively (Figure 3A). Compared to YinHuaLu and JinHuaLu, a smaller proportion of juicy honey peach structure was found in XiaGuang, a yellow-flesh nectarine with a melting texture, which was obtained from BaiHuaShuiMi x [(Precoce de Croncels $\mathrm{x}$ Lord Napier) ${ }^{2}$ x Fantasia] (Figure 3A). Moreover, JinXiu, carrying an admixed structure of southwestern peach I and southern crisp peach, was obtained using the male parent YunShul\#, a released cultivar that was obtained by crossing 2 local cultivars (Figure 3A). FengHuang and LianHuang, 2 released yellow-flesh varieties with admixed structures, were obtained from open pollinated seeds of Early Gold, which was introduced from Japan (Figure 3B). Varieties with an admixed structure of juicy honey peach and southwestern peach I could also be obtained from the cross between 2 occidental varieties (Early Crawford $\mathrm{x}$ Phillips) or between a bred variety and a Japanese variety (JinFeng x Kanto 5) (Figure 3C).

The genetic backgrounds of accessions related to Chinese Cling are listed in Figure 3D. Among the 3 accessions that are similar to Chinese Cling, 2 have a pure structure of juicy honey peach, and the other accession has an admixed structure of juicy honey peach and southwestern peach I. Two of the 5 open pollinated offspring of Chinese Cling carried the pure structure of juicy honey peach, another 2 accessions were admixed with juicy honey peach and southwestern peach I, and the last accession had mostly a juicy peach structure with a little northern peach structure. Some open pollinated offspring of Chinese Cling have a heterozygous genotype for flesh color (Figure 3D).

\section{DISCUSSION}

\section{SSR variability}

The diversity of peach was determined using SSRs in many studies and included commercial varieties from Europe and the USA (Aranzana et al., 2003, 2010), Japanese peaches related to Hakuto (Yamamoto et al., 2003), local cultivars of Spanish peach (Badenes et al., 2002; Bouhadida et al., 2011), Chinese peach landraces (Cao et al., 2012), and a large set of genetic resources worldwide ( $\mathrm{Li}$ et al., 2013). In this study, we used a set of SSRs that was similar to the markers used in studies of 224 occidental commercial varieties and Spanish local varieties (Aranzana et al., 2010) and that was used in the study of 653 peach accessions (Li et al., 2013). Only a small proportion of the material that was used in this study was common to the materials used in previous studies. Thirty-seven of 195 accessions are common in this study and the study by Cao et al. (2012), and 43 accessions, including 10 modern varieties, 30 local cultivars, and 3 wild species, are the same as in the study by Li et al. (2013). The observed alleles and the numbers of genotypes detected in this study were 13.22 and 27.00, respectively, which was higher than those observed in the peach landraces (Cao et al., 2012), higher than those detected in occidental collections (Aranzana et al., 2010), and similar to observations in a large collection of 653 peach accessions (Li et al., 2013). The observed heterozygosity and expected heterozygosity were 0.42 and 0.72 , respectively, which were also 
similar to the values from 653 peach accessions ( $\mathrm{Li}$ et al., 2013) and higher than the occidental collections (Aranzana et al., 2010). SSR evaluation of local cultivars in this study predicted a broad level of diversity. The following reasons could explain the diversity and heterozygosity: the history of peach domestication could be traced back 4000 years in China, and the earliest record of the peach grafting technique appeared as early as 1231 (Wang and Zhuang, 2001). The long history gave Chinese peach growers time to select diverse local cultivars. Propagation by grafting could conserve the selected cultivars and also the heterozygosity. Some local cultivars tested in this study could be very old because they still use the same names as those recorded in ancient references. For example QiuBaiTao was recorded as the same name 1600 years ago, HeHuanErSe and FeiTao were recorded 900 years ago, and YanZhiTao was recorded 800 years ago (Wang and Zhuang, 2001).

\section{Population structure of local peach cultivars}

The population structure was already used in peach to understand the genetic background of different collections. Aranzana et al. (2010) observed 3 stable subpopulations, including melting nectarines, melting peach, and non-melting peach, in 224 peach cultivars including North American and European commercial varieties, old Spanish varieties, and several founders used in the early USA peach breeding programs. By adding more materials, Li et al. (2013) observed 3 subpopulations: oriental, occidental, and landraces. The oriental subpopulation could be divided into 2 different subpopulations: Yu Lu and Hakuho. The occidental accessions were also divided into nectarine and peach subpopulations. The landrace subpopulation could be divided into Spanish, Shanxi, Shaanxi, and wild. In a collection including 94 peach cultivars, 2 obvious subpopulations were modern cultivars and local Spanish cultivars (Forcada et al., 2013). In a collection of 104 peach landraces, 5 subpopulations were predicted, and multiple backgrounds were observed in a single ecological region, but the study did not emphasize the population structure (Cao et al., 2012). In this study, 8 subpopulations could capture the main structure of local cultivars and were biologically interpretable. However, more subpopulations could be observed in wild peach and ornamental peach if more accessions were added to the analysis. For example, when K =9, Yue 192, NanShanTianTao, and HuoLianJinDan were split from the wild peach group, and the 3 accessions were characterized as low chilling peach (about $200 \mathrm{~h}$ ) from southeast China.

The population structure can help us to understand the genetic composition of some special accessions. XuanChenTianTao, which was characterized as a crisp peach, was actually an admixed accession that carried $41 \%$ juicy honey peach, $31 \%$ wild peach, $19 \%$ southwestern peach II, and 9\% southern crisp peach. YeJiHong, a blood-flesh peach similar to the accession carrying the $D B F$ gene (Shen et al., 2013a), has 50\% of the background of crisp peach and another $50 \%$ of wild peach. YanZhiTao with a red mid-rib, which is a $b f b f$ blood-flesh genotype (Werner et al., 1998), was a mixture of ornamental peach, southwestern peach I, Buddha peach, and southern crisp peach in portions of $39,21,20$, and $20 \%$, respectively. HunChunTao, an accession resistant to $-30^{\circ} \mathrm{C}$, has $59 \%$ of the ornamental peach, $27 \%$ of the north peach, and $14 \%$ of the $P$. davidiana composition. HunChunTao was probably introduced to the cold region for ornamental use, and it survived there because of its cold resistance. The genetic background profiles obtained in this study will be useful to select parent lines for breeding. 


\section{Genetic relationships and evolution of local peach cultivars}

The relationships and evolution of different groups of peach were described in the book Peach Flora (Wang and Zhuang, 2001). The evolution diagram was proposed and drawn by considering multiple factors including agronomic traits, palynology, isozyme, geographical distribution, and history, but it was not drawn considering evidence at the molecular level (Figure 4A). However, 3 pathways were not well explained in light of the genetic information provided by this study (Figure 4A, red). First, it was suggested that the northwest peach was derived from wild $P$. persica directly. Because all genetic backgrounds of northwest peach could be found in southwestern peach, we cannot exclude the possibility that northwest peach was derived from southwestern peach. Furthermore, the southwestern peach is geographically closer to the center of origin of peach than the northwest peach. Second, the suggestion that southern crisp peach was derived from northern crisp peach is not supported by the genetic evidence presented in this study (Figure 4A). Third, the genetic evidence presented in this study did not support the view that southern juicy honey peach was derived from northern honey peach (Figure 4A).

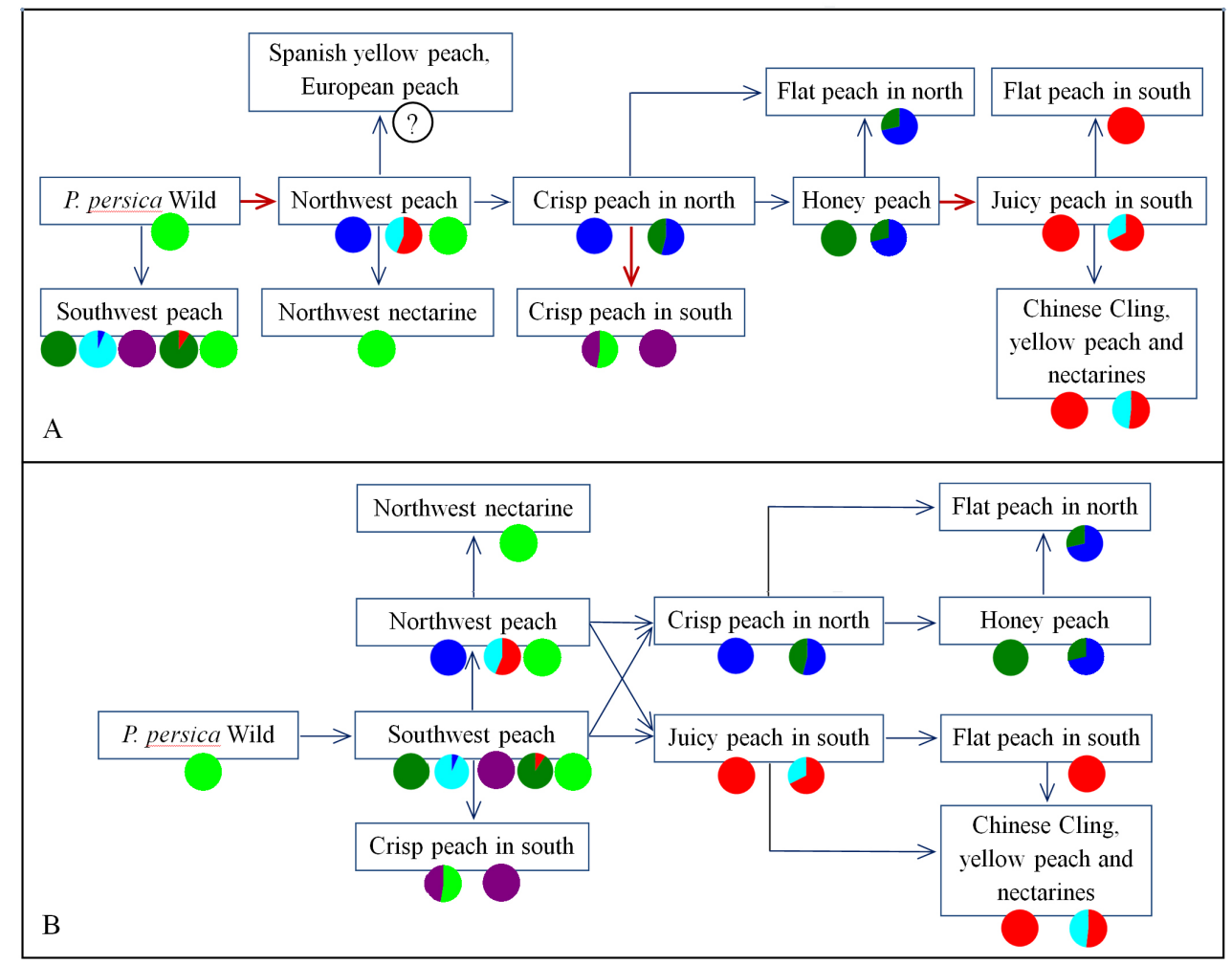

Figure 4. Evolutionary pathway of local peach cultivars in China. The pie charts were drawn according to the Q value of typical accessions when $\mathrm{K}=8$. A. Evolutionary pathway concluded by Wang and Zhuang (2001). Red arrows show the pathways that could not be well explained by the composition of genetic background. B. Modified evolutionary pathway proposed in this study in the light of an understanding of genetic relationships and population structures. 
A modified evolutionary pathway is proposed according to the genetic backgrounds of the accessions identified by SSR (Figure 4B). P. mira, the ancestor of peach, was verified to originate in southwest China (Wang and Zhuang, 2001). It has been suggested that $P$. persica evolved from $P$. mira because many intermediates between $P$. mira and wild $P$. persica could be found in southwest China (Wang and Zhuang, 2001). Usually, more diversity can be found in the center of origin or the region close to it. In this study, we found more diversity in southwestern peach, which included southwestern peach I, southwestern peach II, southern crisp peach, wild peach, northern peach, and juicy honey peach. This level of diversity could be obtained from the wild P. persica over a very long period. The genetic background of 4 traditional groups, including northwest peach, southern crisp peach, southern juicy peach, and northern crisp peach, could all be found in southwestern peach. The southwestern peach could be the genetic origin from which the 4 groups were derived. Therefore, the southern juicy peach, which is also called juicy honey peach, could be derived from southwestern peach and northwest peach because both genetic backgrounds could be found. Flat peach in the south and Chinese Cling were derived from southern juicy peach (Figure 4B). Considering their genetic background, northern crisp peach could also be derived from southwestern peach and northwest peach, but it was more probable that it was derived from northwest peach because it is distributed along the Yellow River, which is the mother river of Chinese culture. Honey peach in the north and flat peach in the north were derived from northern crisp peach because they had similar backgrounds (Figure 4B).

Diverse ornamental peach accessions were investigated in this study, including those with different tree habits (normal, dwarf, weeping, and pillar), different flower color (white, pink, red, and variegated), and different leaf color (green and purple). Unfortunately, places of origin for most ornamental peaches were not clear (Table S1), and some accessions containing ornamental backgrounds are distributed widely (Figure 2). LuoYangHuaMuJi (LuoYang flower and tree collections), a book written by ShiHou Zhou (1081 AD) records 30 peach varieties that were collected in central China (Wang and Zhuang, 2001). Among these varieties, ErSeTao (double colored peach), HeHuanErSeTao (double colored happiness peach), QiangYeFeiTao (double pink flower peach), and ZiYeDaTao (purple-leaved big peach) are ornamental peach varieties. This could explain why ornamental peaches were listed in central China in a previous study (Cao et al., 2012). However, it is uncertain whether the peaches recorded in the book LuoYangHuaMuJi were collected from other regions or if they originated from LuoYang. For this reason, more evidence is needed to deduce the places of origin and derivations of ornamental peach.

\section{Use of local cultivars: current status and prospects}

Compared to the USA and European countries, China was relatively late in adopting modern systematic peach breeding and has a history of only about 60 years. To speed qualityorientated breeding, Hakuto, Okubo, and Hakuho from Japan were used as the parents because of their sweet taste and good fruit size. They were then crossed with juicy honey peach or honey peach from the north to select white peaches for the fresh market. In yellow-fleshed peach breeding for canning or fresh eating, introduced varieties including Early Crawford, Phillips and Early Gold were initially used as parents and crossed with juicy honey peach or northern honey peach. To breed nectarines, Fantasia, Armking, and Legrand were introduced and used as parents. All of these introduced varieties were found to have a narrow genetic background 
(Aranzana et al., 2003; Yamamoto et al., 2003) and could be traced to Chinese Cling or closely related accessions (Layne and Bassi, 2008; Aranzana et al., 2010). The introduced varieties were crossed with local cultivars that were close to Chinese Cling, also causing the limited genetic background of most modern varieties (Figures 2 and 3), although more than 200 commercial varieties were released in China in the last 3 decades.

Honey peach was used in peach breeding programs in the USA and Europe for a long time. It permitted the harvest of fruit earlier without adversely affecting the taste. There are many examples of the use of this type of peach. Combining flat, low-acid, and nectarine, a sweet, flat nectarine (Platerine) was obtained. Using Lukens Honey, an accession native to southern China, Chaffey and Honeyberta were selected (Layne and Bassi, 2008). Using Kiang- $\mathrm{Si}$, an accession that is also from southern China, the low-acid locus $(D)$ was fine mapped (Boudehri et al., 2009). Both Lukens Honey and Kiang-Si were from southern China, had sweet fruit, and could be close to Chinese Cling or closely related accessions. Juicy honey peach was characterized as having a soft melting texture and sweet taste, and it was traditionally preferred by consumers from southern China. However, the real honey peach according to Chinese people was from north China and was characterized as having white flesh, a hard melting texture, and very sweet taste. Northern honey peach differs from juicy honey peach mainly in that it has a hard melting texture, less juice, and a different genetic background as identified in this study (Figure 4). Buddha peach is a typical northern honey peach and was used in Chinese breeding programs to improve the soluble solids content ( ${ }^{\circ}$ Brix). For example, ChiYuanMi, a very sweet variety that was used in this study, was bred by crossing Buddha peach with juicy honey peach. The slow ripening of the fruit and low density of flowers could be good reasons to use the northern honey peach in future breeding programs.

The genetic background of northern peach, ornamental peach, and wild peach found in modern varieties indicates the use of diverse local cultivars in recent breeding programs (Figure 2). However, we did not identify the background of southern crisp peach (violet) among them except as a very small portion of JinXiu (Figure 2). Southern crisp peach is ignored by breeders because of its mealy texture and the strong heritability of its sharp fruit tip. However, they have recently been used in breeding programs to select blood flesh because most local blood-flesh cultivars carrying $D B F$ belong to this group (Shen et al., 2013a). They have also been used as genetic materials to provide resistance to peach gummosis because highly resistant accessions were only found in this group (Ma et al., 2002). Additional important agronomic characteristics will be evaluated in local cultivars, especially those with resistance to diseases and pests. With the facility of peach sequencing (Arús et al., 2012; Verde et al., 2013), more and more genes will be discovered and characterized in local Chinese cultivars, which have a high level of genetic diversity that was confirmed in this study.

\section{ACKNOWLEDGMENTS}

Research funded by the Natural Science Foundation of China (\#30871681,\#31101517), the Project for Preservation and Use of Crop Germplasm Resources in China (\#NB2011-213013507), and the Agricultural Program for Innovation of Jiangsu Province (\#CX(12)5034). Great thanks are given to the former scientists at Jiangsu Academy of Agricultural Sciences who engaged in collecting the local cultivars. Their efforts accumulated and protected valuable genetic resources for this study. Great thanks are given to Pere Arùs and Maria Jose Aranzana from IRTA for their assistance with genotyping. Great thanks are also given to Aihua Gao and 
Stephen Sexton for their English revisions. Jiangsu Academy of Agricultural Sciences and Nanjing Agricultural University contributed the same to this study.

\section{Supplementary material REFERENCES}

Aranzana MJ, Carbó J and Arús P (2003). Microsatellite variability in peach [Prunus persica (L.) Batsch]: cultivar identification, marker mutation, pedigree inferences and population structure. Theor. Appl. Genet. 106: 1341-1352.

Aranzana MJ, Abbassi EK, Howad W and Arús P (2010). Genetic variation, population structure and linkage disequilibrium in peach commercial varieties. BMC Genet. 11: 69.

Arús P, Verde I, Sosinski B, Zhebentyayeva T, et al. (2012). The peach genome. Tree Genet. Genom. 8: 531-547.

Badenes MI, Cuenca J, Romero C, Martinez J, et al. (2002). Description of peach cultivars from Spain: identification of closely related clones by SSR markers. Acta Hortic. 592: 211-216.

Bernatzky R and Tanksley SD (1986). Genetics of actin-related sequences in tomato. Theor. Appl. Genet. 72: 314-321.

Boudehri K, Bendahmane A, Cardinet G, Troadec C, et al. (2009). Phenotypic and fine genetic characterization of the $D$ locus controlling fruit acidity in peach. BMC Plant Biol. 9: 59.

Bouhadida M, Moreno MA, Gonzalo MJ, Alonso JM, et al. (2011). Genetic variability of introduced and local Spanish peach cultivars determined by SSR markers. Tree Genet. Genom. 7: 257-270.

Cao K, Wang L, Zhu G, Fang W, et al. (2012). Genetic diversity, linkage disequilibrium, and association mapping analyses of peach (Prunus persica) landraces in China. Tree Genet. Genom. 8: 975-990.

Cheng $Z$ and Huang H (2009). SSR fingerprinting Chinese peach cultivars and landraces (Prunus persica) and analysis of their genetic relationships. Sci. Hortic. 120: 188-193.

Cipriani G, Lot G, Huang WG, Marrazzo MT, et al. (1999). AC/GT and AG/CT microsatellite repeats in peach [Prunus persica (L) Batsch]: isolation, characterisation and cross-species amplification in Prunus. Theor. Appl. Genet. 99: 65-72.

Dirlewanger E, Cosson P, Tavaud M, Aranzana MJ, et al. (2002). Development of microsatellite markers in peach [Prunus persica (L.) Batsch] and their use in genetic diversity analysis in peach and sweet cherry (Prunus avium L.). Theor. Appl. Genet. 105: 127-138.

Falush D, Stephens M and Pritchard JK (2003). Inference of population structure using multilocus genotype data: linked loci and correlated allele frequencies. Genetics 164: 1567-1587.

FAO (2012). Food and Agriculture Organization of the United Nations. Available at [http://faostat.fao.org]. Accessed February 12, 2014.

Faust M and Timon B (1995). Origin and dissemination of peach. Hortic. Rev. 17: 331-379.

Forcada CF, Oraguzie N, Igartua E, Moreno MÁ, et al. (2013). Population structure and marker-trait associations for pomological traits in peach and nectarine cultivars. Tree Genet. Genom. 9: 331-349.

Gong LZ, He HP, Wang FR and Gu X (2008). Observation of biological characteristics of 10 red-fleshed peach resources in Hubei province. J. Fruit Sci. 25: 413-417.

Hu D, Zhang Z, Zhang D, Zhang Q, et al. (2005). Genetic relationship of ornamental peach determined using AFLP markers. Hortscience 40: 1782-1786.

Infante R, Martínez-Gómez P and Predieri S (2008). Quality oriented fruit breeding: peach [Prunus persica (L.) Batsch]. J. Food Agric. Environ. 6: 342-356.

Layne DR and Bassi D (2008). The peach. Botany, production and uses. CAB International, Wallingford.

Li X, Meng X, Jia H, Yu M, et al. (2013). Peach genetic resources: diversity, population structure and linkage disequilibrium. BMC Genet. 14: 84.

Li Z, Wang YT, Gao L, Wang F, et al. (2014). Biochemical changes and defence responses during the development of peach gummosis caused by Lasiodiplodia theobromae. Eur. J. Plant Pathol. 138: 195-207.

Ma R, Yu M, Du P and Song H (2002). Advances in research of peach gummosis. J. Fruit Sci. 19: 262-264.

Nei M, Tajima FA and Tateno Y (1983). Accuracy of estimated phylogenetic trees from molecular data. J. Mol. Evol. 19: 153-170.

Okie WR, Ramming DW and Scorza R (1985). Peach, nectarine, and other stone fruit breeding by the USDA in the last two decades. Hortscience 20: 633-641.

Pritchard JK, Stephens M and Donnelly P (2000). Inference of population structure using multilocus genotype data. Genetics 155: 945-959.

Rohlf FJ (2000). NTSYS-PC, Numerical Taxonomy System for the PC, ExeterSoftware, Version 2.1. Applied Biostatistics 
Inc, Setauket.

Scorza R, Mehlenbacher SA and Lightner GW (1985). Inbreeding and coancestry of freestone peach cultivars of the eastern United States and implications for peach germplasm improvement. J. Am. Soc. Hortic. Sci. 110: 547-557.

Serrano B, Gomez-Aparisi J and Hormaza JI (2002). Molecular fingerprinting of Prunus rootstocks using SSRs. J. Hortic. Sci. Biotech. 77: 368-372.

Shen ZJ, Ma RJ, Yu ML, Xu JL, et al. (2012). Evaluation of antioxidant factors in peach with three types of flesh color. Sci. Agric. Sinica. 45: 2232-2241.

Shen ZJ, Confolent C, Lambert P, Poëssel JL, et al. (2013a). Characterization and genetic mapping of a new blood-flesh trait controlled by the single dominant locus $D B F$ in peach. Tree Genet. Genom. 9: 1435-1446.

Shen ZJ, Ma RJ, Yu ML, Cai ZX, et al. (2013b). Establishment of peach primary core collection based on accessions conserved in National Fruit Germplasm Repository of Nanjing. Acta Hortic. Sinica 40: 125-134.

Testolin R, Marrazzo T, Cipriani G, Quarta R, et al. (2000). Microsatellite DNA in peach (Prunus persica L. Batsch) and its use in fingerprinting and testing the genetic origin of cultivars. Genome 43: 512-520.

Verde I, Abbott AG, Scalabrin S, Jung S, et al. (2013). The high-quality draft genome of peach (Prunus persica) identifies unique patterns of genetic diversity, domestication and genome evolution. Nat. Genet. 45: 487-494.

Wang ZH and Zhuang EJ (2001). The China fruit plant monograph-peach flora. Chinese Forest Press, Beijing, 1-51.

Werner DJ, Creller MA and Chaparro JX (1998). Inheritance of the blood-flesh trait in peach. Hortscience 33: 1243-1246.

Yamamoto T, Mochida K and Hayashi T (2003). Shanhai Suimitsuto, one of the origins of Japanese peach cultivars. $J$. Jpn. Soc. Hortic. Sci. 72: 116-121.

Yeh FC, Yang RC and Boyle T (1999). POPGENE Microsoft Window-based freeware for population genetic analysis. A joint project development by Fancis C. Yeh and Rong-Cai Yang, University of Alberta and Tim Boyle, Centre for International Forestry Research, Bogor.

Yu ML (2004). Genetic evaluation of main characters and study of molecular marker technique in peach. Doctoral thesis, Nanjing Agricultural University, Nanjing. 